\title{
Helicobacter pylori infection and related factors among pregnant women at Debre Tabor General Hospital, Northwest Ethiopia, 2021
}

Hiwot Yisak ( $\sim$ hyisak@yahoo.com )

Debre Tabor University https://orcid.org/0000-0003-2922-289X

debaka

debre tabor university

yeserk

debre tabor university

\section{Research Article}

Keywords: Helicobacter pylori infection, pregnant women, Debre Tabor

Posted Date: November 11th, 2021

DOI: https://doi.org/10.21203/rs.3.rs-1068436/v1

License: (c) (i) This work is licensed under a Creative Commons Attribution 4.0 International License.

Read Full License 


\section{Abstract}

Introduction: Infection with Helicobacter pylori is one of the most frequent chronic bacterial illnesses in humans, infecting more than half of the world's population.

Pregnant mothers are the populations most vulnerable to Helicobacter pylori infection. The frequency of $\mathrm{H}$. pylori infection during pregnancy varies greatly depending on where you live. The objective of his study was to assess the prevalence of Helicobacter pylori infection and associated factors among pregnant mothers following antenatal care at antenatal care clinic in Debre Tabor General Hospital, Debre Tabor, Ethiopia, 2021.

Methods and materials: Institutional based cross-sectional study design was conducted.

Bivariate and multivariate logistic regression analyses were carried out to assess potential factors with Helicobacter pylori infection. Variables associated with the prevalence of Helicobacter pylori infection with ( $p$-value $<0.05$ ) were considered as significant factors.

Results: The prevalence of Helicobacter Pylori infection was 52(17.9\%), with 95\% (Cl: $13.4-22.3 \%)$. Sixty-five point four percent (65.4\%) of Helicobacter Pylori infection positive mothers had gastrointestinal problems and developed symptoms like abdominal cramp and diarrhea $01(1.92 \%)$, loss of appetite10 (19.23\%), hiccups $9(17.31 \%)$, abdominal pain i.e. worsen when the stomach is empty $19(36.54 \%)$, indigestion and frequent heart burn $13(25 \%)$ during the present pregnancy. Lesser frequency of hand washing practice $A O R=3.09,95 \% \mathrm{Cl}(1.14-8.34)$. Use of soap for hand washing $\mathrm{AOR}=0.44,95 \% \mathrm{Cl}(0.19$ $0.98)$, feeding unwashed vegetables and fruits $A O R=2.279,95 \% \mathrm{Cl}(1.03-5.04)$, not being anemic $A O R$ $=0.268,95 \% \mathrm{Cl}(0.10-0.71)$, were significantly associated with Helico bacter pylori infection.

Conclusions: This study shows that the prevalence of $\mathrm{H}$. pylori infection was not low. The levels of anemia which was strongly associated with the prevalence of $\mathrm{H}$. pylori infection. This implies that Helicobacter Pylori infection is a public health problem.

\section{Introduction}

\section{Background}

Helicobacter pylori is a gram-negative, spiral-shaped, microaerophilic bacteria that causes inflammation of the stomach lining and can be found in the stomach $(1,2)$. It's possible that it's the most common bacterial illness on the planet, infecting about half of individuals in rich countries and $80 \%$ of people in underdeveloped ones (3-8) in which developing countries have the highest prevalence when compared to developed countries $(7,9-12)$.

Helicobacter pylori is a common gut infection that is known to cause duodenal and gastric ulcers, as well as being a major risk factor for stomach cancer $(2,3,13-17)$; the severity of infection varies around the world depending on public health actions. H. Pylori primarily infects the antrum of the stomach mucosa, 
causing acute and chronic inflammation. Peptic ulcer, adenocarcinoma, and stomach lymphoma are all linked to this illness $(18-20)$. H. pylori is classified as a class 1 carcinogen by the World Health Organization $(17,21-23)$.

The World Health Organization (WHO) has issued a list of 16 bacteria that are considered high priority pathogens and pose the greatest threat to human health (10).

Because of decreased gastric acid production during early pregnancy, which results in increased accumulation of woman's body fluid, steroid hormone changes, and immunologic tolerance could lead to the activation of latent $\mathrm{H}$. pylori infection, which can exacerbate nausea and vomiting, pregnancy increases susceptibility to $\mathrm{H}$. pylori infection $(24,25)$. Pregnant moms are the most sensitive to the infection; epigastric pain/dyspepsia, flatulence, fullness, nausea, vomiting, anemia, fetal development restriction, fetal abnormalities, and low birth weight are all clinical signs of H.pylori infection $(2,3,14,26)$. Early pregnancy nausea and vomiting are frequent, affecting 50 percent to 90 percent of pregnant women in the first half of their pregnancy, and can have a significant impact on maternal health and quality of life $(27,28)$.

Morning sickness, often known as nausea and vomiting during pregnancy, affects 70-80 percent of all pregnancies in the first trimester. It usually begins between 4 and 8 weeks of pregnancy, however symptoms can last until the 16th-18th week. It's usually a minor problem that goes away on its own. (29). H. pylori infection is a serious health condition that can develop at any age and results in silent chronic infection. $(7,30)$ and persists into adulthood. Infection with Helicobacter pylori (H. pylori) during pregnancy is linked to iron deficiency anemia, fetal abnormalities, miscarriage, pre-eclampsia, and fetal growth limitation, in addition to gastrointestinal issues such hyperemesis gravidarum. Helicobacter pylori infections can occur during pregnancy, and they can cause issues such as hyperemesis gravidarum, coronary heart disease, iron deficiency anemia (IDA), diabetes mellitus, cholecystitis, and stomach cancer. $(6,7,9,10,13,16)$. Patients with gastrointestinal symptoms (dyspepsia, gastritis, peptic ulcer, and nausea and vomiting) are more likely to be infected with H.pylori (10).

During pregnancy, the mothers' Helicobacter pylori serostatus was determined. (9). During pregnancy, Helicobacter pylori infection can induce local and inflammatory damage to the stomach epithelium, leading to gastrointestinal problems such hyperemesis gravidarum. Helicobacter pylori sequesters important micronutrients such as iron (Fe) from pregnant mothers, resulting in iron deficiency anemia.(14, 18).

Hyperemesis gravidarum $(\mathrm{HG})$ is a consequence of chronic $\mathrm{H}$. pylori infection in pregnant women that affects 0.3 to 2.0 percent of all pregnancies. $(2,5,10,18,28)$. Helicobacter pylori infection is identified in gastrointestinal disorders and even during pregnancy utilizing a variety of inquiry methods, such as HPSA, an enzymatic immunoassay that detects bacterial antigen of actual continuing infection in the stool. $(5,25)$. 
For 10-14 days, a triple-drug regimen combining two antibiotics and a proton pump inhibitor (PPI) is usually required to treat this infection. (9). There are currently no standards for treating $\mathrm{H}$. pylori infection during pregnancy, and the best treatment remains unknown. (25).

The global prevalence of $\mathrm{H}$. pylori infection in pregnant women was assessed to be 46\%; the lowest and highest frequency of the infection were in Finland in 2000 (7.6\%) and Sudan in 2012 (94\%) respectively, with Europeans accounting for $25 \%$ and South America accounting for $62 \%$ (3).

$\mathrm{H}$. pylori is acquired in early childhood through family members via oral-oral, gastric-oral, or oral-fecal pathways, according to current research, and can last until maturity. $(9,20,30)$; In low-income areas, fecaloral transmission is more common (31). This could have been aided by inadequate environmental cleanliness, overcrowding, and fecal pollution of drinking water sources (21). Various studies from various geographical regions revealed that the prevalence of $\mathrm{H}$. pylori during pregnancy ranged from 7.6 percent to 94 percent in European countries, 24 percent to 61 percent in Asian countries, 50 percent to 70 percent in American countries, and more than 52 percent in Africa (3).

The prevalence of Helicobacter pylori in pregnant women of Western ethnicity is substantially lower than in women of non-Western ethnicity, and the link between $\mathrm{H}$ pylori and severe NVP has been replicated in multiple investigations, mostly in non-Western communities with high $\mathrm{H}$ pylori prevalence(27).

A Nigerian study was conducted. H. pylori can cause the stomach acid barrier to be suppressed, allowing enteropathogens to be swallowed through contaminated weaning foods. This makes it easier to go into the small intestine. This puts children at risk for diarrhea, malabsorption of critical nutrients including vitamin $\mathrm{C}$ and B12, and growth failure(12).

Helicobacter pylori is a common cause of chronic gastritis, peptic ulcer disease, asymptomatic gastric adenocarcinoma, and mucosa-associated lymphoid tissue lymphoma, and it can be contracted during pregnancy(13).

In Ethiopia, the prevalence of helicobacter pylori infection ranged from $7.7 \%$ to 91 percent, indicating that it is a common cause of gastrointestinal disorders (10). H. pylori screening and treatment, which may contribute to significant maternal morbidity.

Hence the objective of this study was to assess the prevalence of Helicobacter pylori infection and associated factors among pregnant women who have antenatal care visits at an antenatal clinic in Debre Tabor General Hospital, Northwest Ethiopia from 01, December,2020 to 30,February, 2021.

\section{Methods And Materials}

\section{Study design}

The study was conducted the institutional-based cross-sectional study design to assess the prevalence of Helicobacter pylori infection and associated factors among pregnant women who have antenatal care 
visits at an antenatal clinic in Debre Tabor General Hospital, Northwest Ethiopia from 01, December 2020 to 30 , February 2021.

\section{Study area and period}

The study was conducted at Debre Tabor town is the capital and woreda of SGAZ in the northwest of Ethiopia which is located in the Amhara Region about 100 kilometers southeast of Gondar and 50 kilometers east of lake Tan. The town has a total population of 83,082 of whom 39,781 are males and 43,301 are females. Debre Tabor general hospital is one of the zonal referral hospitals which are found at Debre Tabor town in south Gondar administrative zone, Amhara region, Northwest Ethiopia at about 668 and 103 kilometers $(\mathrm{km})$ faraway from capital Addis Ababa and Amhara region/ Bahir Dar respectively. According to the current Ethiopian Health Tier system, it serves 1 million to1.5 million people.

\section{Source of the population}

All pregnant women at Debre Tabor town and surrounded rural kebeles.

\section{Study population}

All pregnant mothers having ANC visits during the study period at Debre Tabor General Hospital.

\section{Variables of the study}

Dependent variable:

Prevalence of helicobacter pylori infection.

Independent variables:

Socio-demographic factors

Source of drinking water

Hand washing practice

History of vomiting

Anemic status

Feeding habit of spies food

Numbers of gravidity

Gestational age

History of gastrointestinal discomfort/ illness 


\section{Eligibility criteria}

Inclusion Criteria

All pregnant women who have antenatal care visit at an antenatal clinic in Debre Tabor General Hospital, Northwest Ethiopia from 01, December 2020 to 30, February 2021.

Exclusion Criteria

Pregnant mothers who have a critical illness, not able to give stool samples, and mothers who took anti H.pylori drug before 2 weeks.

\section{Sample size and sampling technique \\ Sample size determination}

The sample size was determined by using a single population proportion formula to obtain the desired sample size and to estimate the magnitudes of helicopter pylori infection. Thus, the sample size was calculated with the assumptions of $95 \%$ confidence level, $5 \%$ margin of error, and by using the previous prevalence study done among women of childbearing age in Addis Ababa, Ethiopia, was $21.9 \%(5)$.

Thus, by applying the formula a sample size of 264 pregnant mothers and the $10 \%$ of unresponsive rate ( $264 \times 10) / 100$ is 26 . Then by adding 26 from the total sample size the minimum final sample size for study subjects was $26+264=290=290$.

\section{Sampling procedure}

After obtaining written consent from each participant, a simple random sampling technique was employed. In the institute, 20 pregnant mothers per day were visited for ANC on average. Therefore, in 22 working days of the month, there were 550 pregnant mothers and for the 3 months, there were 1650 pregnant mothers requested for HPSA. Therefore, to address the study subjects, the sample size was collected proportionally every day according to the number of pregnant mothers visited for ANC during the study period. Thus $\mathrm{k}=\mathrm{N} / \mathrm{n}=>1650 / 290=6$; and then the data will be collected every 6 th pregnant mother who is visiting ANC clinic during data collection priories.

\section{Operational definition}

\section{Pregnancy mothers}

are defined as the development of one or more fetuses in the uterus of a woman.

\section{Prevalence}

is a measurement of pregnant mothers who have been affected by the helicobacter pylori above the average of the study participants at a particular time is high. 


\section{Trimester}

One of the three-month periods into which pregnancy is divided.

\section{Helicobacter pylori stool Antigen test (HPSA)}

is a lateral flow chromatographic immunoassay for the qualitative detection of H.pylori antigen in the human fecal specimen.

\section{Data collection}

Before data collection, adequate training was given for data collectors and supervisors. The training aimed to collect the data correctly and to give a brief explanation to participants. The data was collected using a pre-tested structured questionnaire which contained questions related to socio-demographic characteristics, behavioral habits, and environmental conditions at Debre Tabor health center. There are several laboratory methods available to detect $\mathrm{H}$. pylori infection. Some of these are HPSAT and blood serum tests.

\section{Stool sample collection}

A clean plastic screwed cupped container and wooden applicator sticks were distributed and the participants were instructed to bring stool specimens to the laboratory. Enough amount of fresh fecal samples was collected from each study subject and analysis was done as early as arrived or stored at 2$30^{\circ} \mathrm{C}$ until analysis. At the time of sample collection, the date of sampling, the name of the participant, age, and consistency of the stool (formed, semi-formed and watery) was recorded for each study subject on a recording format and the container.

\section{Determination of H.pylori stool antigen}

Serologic and stool antigen tests are the first choices for $\mathrm{H}$. pylori infection diagnosis in pregnancy since they are easy to perform and low-cost noninvasive diagnostic tests. The stool antigen test is an enzymatic immunoassay that detects the active presence of $\mathrm{H}$. pylori antigen in human feces. Stool antigen test is preferred to determine the presence of $\mathrm{H}$. pylori infection and status after eradication. After fecal sample collection, the HPSA strip was removed from the pouch and placed on a clean, flat surface; the test device was checked for expiration date printed on the sealed pouch; it was brought to room temperature before opening; enough amount of stool sample is added to the bottle in order to make dilute with buffer and the plastic sampling bottle shake thoroughly.

The sample bottle was holding vertical direction in the correct position; then break off the plastic cover carefully; be sure that there are no air bubbles; then add 3-4 drop from the sample solution into dropping hole; read out the test result after 5-10 minute. Do not consider the result after 15 minutes. When an adequate volume of an extracted fecal specimen is dispensed into the sample well of the test cassette, the specimen migrates by capillary action across the cassette. If Helicobacter pylori antigens present in 
the specimen, bind to the anti- Helicobacter pylori conjugates. The immunocomplex is then captured on the membrane by the precoated antibody, forming a burgundy colored at $\mathrm{T}$ band, control indicating Helicobacter pylori-positive test result. The absence of the $T$ band suggests that the concentration of H.pylori antigens in the specimen is below the detectable level, indicating an H.pylori negative test result.

\section{Data quality control}

Before starting the actual work, the quality of the helicobacter pylori antigen testing kit was checked by quality control test (using known positive). The data was collected using a pre-tested structured questionnaire at Debre Tabor health center and all laboratory procedures were supervised and checked by taking $5 \%$ of collected data randomly for its correctness and completeness by the principal investigator daily.

To eliminate observer bias, each stool sample was examined by two laboratory technicians. The technicians were informed about the health status of the study participants. In cases where the results were discordant, a third senior reader is confirmed. The result of the third expert reader was considered the final result.

\section{Data processing and analysis}

The obtained data was checked, edited manually, then coded and entered into Computer using Epi info 7 and exported to the Statistical Package for the Social Sciences (SPSS) version 20. The prevalence of helicobacter pylori infection was presented by frequency distribution tables, percentages, graphs, figures after descriptive statistics were generated.

Bivariate and multivariate logistic regression analyses were carried out to associate potential factors with helicobacter pylori infection. Factors that had bivariate associations with ( $p$-value $\otimes 0.2$ ) entered into multivariate logistic regression for further analysis. Variables associated helicobacter pylori infection with ( $p$-value $\leq 0.05$ ) were considered as significant factors.

\section{Ethical considerations}

The study will be conducted after getting an ethical approval letter from the Institutional Review Board (IRB) of Debre Tabor University (DTU). Informed written consent was obtained from individuals included in the study participants. Participants were also informed that all personal information was treated strictly confidential. The study participants were found positive for helicobacter pylori infection treated with fist line drugs ordered by a physician from the Debre Tabor general hospital.

\section{Result}

\section{General Characteristics of the Study Participants}

A total of 290 study subjects have participated. The mean age was 26.59 with the STD \pm 4.23 years the age range was 22 years, the minimum and maximum age were 18 and 40 respectively. The religion of the 
participants was Orthodox Christian 227 (78.3\%), followed by Muslim 32 (11\%). About 45.5\% had attained primary school and $92.4 \%$ were married. Almost $78.3 \%$ of the women were orthodox Christian which is the largest Amhara ethnic group. Among the participants, 104(35.9\%), 68 (23.4\%), 32 (11. \%), 68 (23.4\%), 18(6.2\%) were housewife farmers, governmental employees, merchants, and daily laborers respectively. Regarding the residence, 64(22.1\%) were in urban and 227 (77.9\%) were rural dwellers. (Table: 1).

\section{Prevalence of Helicobacter pylori infection}

The prevalence of Helicobacter Pylori infection was 52(17.9\%), with 95\% (Cl: $13.4-22.3 \%)$. Among this $57.7 \%$ had Ptyalism, nausea, and vomiting during the current pregnancy. This is considered one of its reasons for the Helicobacter pylori infection. About $15.4 \%$ had a history of severe nausea and vomiting in the previous pregnancy.

Sixty-five point four percent (65.4\%) of Helicobacter Pylori infection positive mothers had gastrointestinal problems and developed symptoms like abdominal cramp and diarrhea 01 (1.92\%), loss of appetite10 (19.23\%), hiccups $9(17.31 \%)$, abdominal pain i.e. worsen when the stomach is empty $19(36.54 \%)$, indigestion and frequent heart burn $13(25 \%)$ during the present pregnancy. Considering the gestational age of the Helicobacter pylori infection positive pregnant mothers the least prevalent $9(17.31 \%)$ was the first trimester and the highest prevalence $26(50 \%)$ was the third trimester of gestational age.

Regarding to the levels of anemia for the helicobacter pylori infection positive pregnant mothers $4(7.7 \%)$ had $7-9 \mathrm{~g} / \mathrm{dl}, 12(23.1 \%) 9-11 \mathrm{~g} / \mathrm{dl}, 25(48.1 \%)<7 \mathrm{~g} / \mathrm{dl}$ and $11(21.2 \%)>=12 \mathrm{~g} / \mathrm{dl}$. Furthermore, of the 52 helicobacter pylori infection positive pregnant mothers 23 (44.2\%), 7(13.5\%), 1(1.9), and 21(40.4\%) had A, $B, A B, O$ blood group respectively.

Moreover, Helicobacter Pylori infection positive pregnant mothers with the highest prevalence of $18(34.62 \%)$ had gravida two and the least prevalence $8(15.4 \%)$ had gravida one. (Figure: 1,2$)$

\section{Factors Associated with Helicobacter pylori infection.}

Bivariate analysis was used to explore the association between Helicobacter pylori infection with each of the determinant factors., Residence, Gravidity, Source of drinking water, hand washing practice, materials used to wash hands, feeding unwashed vegetables and fruit, feeding spices foods, availability of latrine at home and its usage habit and levels of anemia have met the criteria $(P<0.2)$ to be further analyzed in multivariate logistic regression analysis.

Variables that had bivariate associations with ( $p$-value $\otimes 0.2$ ) entered into multivariate logistic regression for further analysis. The Factors associated with multivariate logistics regression analysis $(p<0.05)$ with the prevalence of Helicobacter pylori infection were found to be hand wash practice, materials used for hands washing, feeding of unwashed vegetables and fruits, and levels of anemia. 
However, there was no significant association observed with the variables, residence, and gravity, source of drinking water, feeding of spices foods and availability of latrine and its usage habit between the prevalence of Helicobacter pylori infection $(P>0.05)$. (Table-2).

\section{Discussion}

In this study, two hundred ninety (290) consenting pregnant women were recruited and examine for the presence of $\mathrm{H}$. pylori infection. The result revealed that the prevalence rate of $\mathrm{H}$. pylori infection among pregnant women attending Debre Tabor General Hospital was 52(17.9\%).among them

The finding of this study is in line with the study conducted in France(32), A Systematic Review and Metaanalysis Study did in Global prevalence (3)

The prevalence of this study which is higher than the prevalence of previous studies conducted in the Hispanic population (39),

As compared to other previous studies, the prevalence of the current study is much lower than a study conducted in different parts of Ethiopia(5, 10, 19, 40-43) a meta-analysis study in Iran(44), in Rural Durango, Mexico(34), Ilam, Iran(3), in Uganda(6), in Kawempe Health Centre Kampala, the capital city of Uganda (14), Alexandria University, Egypt(2) in Sudan (45), South of Libya(39), University of Maiduguri Teaching Hospital Borno State Nigeria (22) in Sant'Anna Hospital of Turin, Italy(36), in Netherland(27), Ardabil, Chile(18), Urmia University, Iran(28), Bio Bio Province. VIII Region. Chile(33), Alagouza Police Authority Hospital Cairo, Egypt(36), in Abakaliki, South Eastern Nigeria(26), Aerospace Center Hospital in Beijing, China(30), Keffi, Nasarawa State, Nigeria (11) in Tehran-Iran (46), in Turkey (47). This difference may be due to the method used and sensitivity/specificity of the laboratory to detect $\mathrm{H}$. pylori infection, time of study periods, and geographical variation of factors across different areas, poor personal and environmental hygiene, behavioral factors, and socioeconomic status of individuals.

All variables were analyzed first using bivariate binary logistic regression and all bivariate results that had a $p$-value $<0.2$ entered into multivariate logistic regression analysis. The variables significantly associated with multivariate logistics regression analysis $(p \leq 0.05)$ were handwashing practice, materials used to hand washing, feeding of unwashed vegetables and fruits, and levels of anemia with the prevalence of Helicobacter pylori infection.

The Levels of anemia was found to be significant factors strongly associated with the prevalence of Helicobacter pylori infection. pregnant women who had levels of anemia $\geq 12 \mathrm{~g} / \mathrm{dl}$ with AOR $[95 \% \mathrm{Cl}$ : $0.268[0.101-0.711]$ was $27 \%$ times less likely to have Helicobacter pylori infection as compared to those who had a level of anemia $<7 \mathrm{~g} / \mathrm{dl}$; this is consistent with the study conducted in the Kulito Health Center, Halaba Zone, South Ethiopia(41), Boditii Health Center, Southern Ethiopia(48), Arba Minch Town, Gamo Gofa Zone, Ethiopia(42), in Tehran-Iran (46), Ilam, Iran. (49). The probable reason for this study could be due to some possible mechanisms by which Helicobacter pylori impacts iron metabolism by decreased absorption. Helicobacter pylori infection developed chronic gastric ulceration this decreased hydrochloric 
acid (ascorbic acid secretion) concentration which increased hepcidin production associated with Helicobacter pylori gastric ulceration leading to reduced intestinal iron absorption. H.pylori can be expected not to survive in acidic gastric conditions produced by the acidic citrus fruits. When the uptake of iron by Helicobacter pylori for growth does not occur, increased availability of iron in lactoferrin in the gastric mucosa and the absorption of iron is not affected. On the other hand, bacterium host competition does not occur for dietary iron supply $(14,41,47)$.

Hand washing practice found to be another significant factor associated with the prevalence of Helicobacter pylori infection and participants who had practiced hand washing sometimes with AOR [95\% Cl: 3.090[1.144- 8.348] were 3.1 times more likely to have the Helicobacter pylori infection as compared to who had practiced hands washing immediately after contact with dirt which is consistent with other studies done in Ethiopia(10,50), University of Maiduguri Teaching Hospital Borno State Nigeria(22), Alaska Area Indian (17); this suggest that mode of transmission of $\mathrm{H}$. pylori could be the result from the fecal-oral route that can relate to poor hygienic practices (handwashing). Ingestion is not the only means of transmission potentially affected by water. Sometimes handwashing practice was associated with the prevalence of $\mathrm{H}$. pylori infection(17).

Materials used to wash hands was found to be another factor associated with the prevalence of Helicobacter pylori infection. Participants who used water and soap to wash hands with AOR [95\% Cl: $0.439[0.196,0.983]$ were $44 \%$ times less likely to have Helicobacter pylori infection as compared to those who had use water only; this is consistent in. The reason for this may be a soap removed the bacterium because it decreases the water surface tension. On the other hand, some soaps had an anti-bacterial effect so that it killed the bacterium.

Feeding unwashed and raw vegetables and fruits was found to be another factor associated with the prevalence of Helicobacter pylori infection and study participants who had feed unwashed vegetables and fruits with AOR [95\% Cl: 2.279[1.031-5.037] were 2.3 times more likely to have Helicobacter pylori infection as compared to who had feed unwashed vegetables and fruits which is consistent a study conducted in Jigjiga University, Jigjiga, Somali Regional State of Ethiopia(20) University of Gondar Hospital, Gondar, Ethiopia (19). The probable reason could be the bacterium may contaminate the vegetable and fruit directly from the environment or the vegetable and fruit did plant on the contaminated soils/environment.

In bivariate logistic regression source of drinking water was showed that pregnant mothers who drank well water were slightly higher Helicobacter pylori infection than those who used tap water $(P<0.2)$. Among $52 \mathrm{H}$. pylori, pregnant mothers $67.31 \%$ had access to a latrine and its usage habit as compared to $32.7 \%$ prevalence in those who had no access to a latrine and its usage habit $(p<0.2)$. Which similar to the study done in Northwest Ethiopia $(19,20,40)$ The reason for this might be due to the more likelihood of fecal contamination of well water when compared to tap water which is regularly treated before distribution. 
There was a significant association between the prevalence of $\mathrm{H}$. pylori pregnant infection and residence with OR [95\% Cl: $0.405[0.211-0.777]$. the probable reason could be connected with the exposure to environmental pollution and other risk factors that facilitate the acquisition of the infection.

The prevalence of $\mathrm{H}$. pylori pregnant infection in pregnant mothers who eating spicy foods $(7.24 \%)$ was lower than those who feed non-spicy foods (50\%). However, there was an association observed between the prevalence of $\mathrm{H}$. pylori infection and pregnant mothers who feed spicy foods in the present study $(p<0.2)$.

\section{Strength}

Use of HPSAT diagnostic methods to detect the H.pylori for which stool antigen tests is one of the first choices.

\section{Limitation}

The limitation of this study is that used the H.pylori stool antigen test only. Using multiple diagnostic methods increases the detection of $\mathrm{H}$. pylori infection. However, the stool antigen test has been used widely in Africa.

\section{Conclusion}

This study shows that the prevalence of $\mathrm{H}$. pylori infection among our sample population is low. The levels of anemia which was strongly associated with the prevalence of $\mathrm{H}$. pylori infection, hand washing, feeding of unwashed vegetables and fruit, materials used to wash hands significantly associated with the prevalence of Helicobacter pylori infection. This implies that $\mathrm{H}$. pylori infection is a public health problem.

\section{Recommendation}

Even though the prevalence of $\mathrm{H}$. pylori infection was low, a constant check of the H. pylori infection in pregnancy, regular hand washing using water and soap, and improvement of education levels in women of gestational age take to action.

Health professionals should promote the importance of personal hygiene including regular hand washing after visiting the toilet to combat fecal-oral transmission.

The Woreda Health Office could plan and strengthen awareness creation programs on the transmission routes and prevention mechanisms of $\mathrm{H}$. pylori infection to reduce the burden. Other researchers could conduct community-based studies in the general population to understand the burden of the infection.

\section{Declarations}




\section{Ethics approval and consent to participate}

This study have been performed in accordance with the Declaration of Helsinki. Ethical clearance was obtained from Debre Tabor University College of medicine \& health science ethical review committee. Then, the participants of the study were informed about the purpose of the study, the importance of their participation, and their right to withdraw at any time. All methods were carried out in accordance with ethical guidelines and regulations. Informed consent was obtained prior to data collection. To keep the confidentiality of clients' data, their names was not document.

\section{Consent to publish}

All the authors have agreed and gave consent for the publication

\section{Availability of data and materials}

The datasets used during the current study are available from the corresponding author on a reasonable request.

\section{Competing of interest}

All authors declared that there is no competing interest at all.

\section{Funding statement}

The author(s) received no financial support for the research, authorship, and/or publication of this article.

\section{Authors' contributions}

HY, BB and YM made substantial contributions to conception and design, acquisition of data, or analysis and interpretation of data. HY took part in drafting the article or revising it critically for important intellectual content. All authors agreed to submit to the current journal; gave final approval of the version to be published; and agree to be accountable for all aspects of the work.

\section{Acknowledgement}

The authors would like to thank the participants of the study and officials in South Godar Zone and Debre Tabor Hospital .

\section{References}

1. Mabeku LBK, Ngamga MLN, Leundji H. Potential risk factors and prevalence of Helicobacter pylori infection among adult patients with dyspepsia symptoms in Cameroon. BMC infectious diseases. 2018;18(1):278. 
2. Elmahdy M, Elmarsafawy A, Elkafash D. Association between helicobacter pylori infection and hyperemesis gravidarum. Int J Reprod Contracept Obstet Gynecol. 2017;5(9):3175-80.

3. Azami M, Nasirkandy MP, Mansouri A, Darvishi Z, Rahmati S, Abangah G, et al. Global prevalence of helicobacter pylori infection in pregnant women: a systematic review and meta-analysis study. Int $\mathrm{J}$ Women's Health Reprod Sci. 2017;5(1):30-6.

4. Farag TH, Stoltzfus RJ, Khalfan SS, Tielsch JM. Helicobacter pylori infection is associated with severe anemia of pregnancy on Pemba Island, Zanzibar. The American journal of tropical medicine and hygiene. 2007;76(3):541-8.

5. Kitale KT, Sori LM, Desalegn DM, Tullu KD. The burden of Helicobacter pylori Infections and Associated Risk Factors among Women of Child-Bearing Age in Addis Ababa, Ethiopia. International journal of chronic diseases. 2018;2018.

6. Baingana RK, Enyaru JK, Davidsson L. Helicobacter pylori infection in pregnant women in four districts of Uganda: role of geographic location, education, and water sources. BMC Public Health. 2014;14(1):915.

7. Alshareef SA, Rayis DA, Adam I, Gasim GI. Helicobacter pylori infection, gestational diabetes mellitus, and insulin resistance among pregnant Sudanese women. BMC research notes. 2018;11(1):517.

8. Smith S, Fowora M, Pellicano R. Infections with Helicobacter pylori and challenges encountered in Africa. World journal of gastroenterology. 2019;25(25):3183.

9. Goodman KJ, O'rourke K, Day RS, Wang C, Redlinger T, Campos A, et al. Helicobacter pylori infection in pregnant women from a US-Mexico border population. Journal of immigrant health. 2003;5(3):99-107.

10. Melese A, Genet C, Zeleke B, Andualem T. Helicobacter pylori infections in Ethiopia; prevalence and associated factors: a systematic review and meta-analysis. BMC gastroenterology. 2019;19(1):8.

11. Oti B, Pennap R, Dennis O, Ajegena S, Adoga P. Prevalence and predictors of Helicobacter pylori infection among patients attending a healthcare facility in North-Central Nigeria. Asian Pacific Journal of Tropical Disease. 2017;7(6):352-5.

12. Senbanjo IO, Oshikoya KA, Njokanma OF. Helicobacter pylori associated with breastfeeding, nutritional status, and recurrent abdominal pain in healthy Nigerian children. The Journal of Infection in Developing Countries. 2014;8(04):448-53.

13. Al-Balushi MS, Anthony Said E, Syed Hasson S, Zaid Al-Busaidi J, Al-Reesi I, Idris M, et al. High Levels of IgA Antibodies to Helicobacter Pylori among Omani Women during Pregnancy and after Delivery. Iranian Journal of Immunology. 2016;13(2):114-23.

14. Baingana RK, Enyaru JK, Tjalsma H, Swinkels DW, Davidsson L. The etiology of anaemia during pregnancy: a study to evaluate the contribution of iron deficiency and common infections in pregnant Ugandan women. Public health nutrition. 2015;18(8):1423-35.

15. Everhart JE, Kruszon-Moran D, Perez-Perez GI, Tralka TS, McQuillan G. Seroprevalence and ethnic differences in Helicobacter pylori infection among adults in the United States. The Journal of infectious diseases. 2000;181(4):1359-63.

Page $14 / 21$ 
16. Al Dossari K, Kamal S, Al-Malki A, Al-Zahrani J. Prevalence and Associated Factors of Pylori Infection in Symptomatic Patients Admitted to A Major Hospital in Saudi Arabia. Journal of Health Informatics in Developing Countries. 2016;10(1).

17. Miernyk KM, Bulkow LR, Gold BD, Bruce MG, Hurlburt DH, Griffin PM, et al. Prevalence of Helicobacter pylori among Alaskans: Factors associated with infection and comparison of urea breath test and anti-Helicobacter pylori IgG antibodies. Helicobacter. 2018;23(3):e12482.

18. Monje ME, Vega AM, Valdés LM, Cancino AG. Helicobacter pylori and perinatal pathologies: pathogen transmission during childbirth? Biology and Medicine. 2016;8(5):1.

19. Negash M, Wondifraw Baynes H, Geremew D. Helicobacter pylori Infection and Its Risk Factors: A Prospective Cross-Sectional Study in Resource-Limited Settings of Northwest Ethiopia. Canadian Journal of Infectious Diseases and Medical Microbiology. 2018;2018.

20. Alebie G, Kaba D. Prevalence of Helicobacter pylori infection and associated factors among gastritis students in Jigjiga University, Jigjiga, Somali Regional State of Ethiopia. J Bacteriol Mycol. 2016;3(3):00060.

21. Bello AK, Umar AB, Borodo MM. Prevalence and risk factors for Helicobacter pylori infection in gastroduodenal diseases in Kano, Nigeria. African Journal of Medical and Health Sciences. 2018;17(1):41.

22. KOLO B, MUHAMMAD I, DAWUD H. MA ISA*, CU ONUEGBU**, AU BULAKARIMA.

23. Samie A, Tanih NF, Ndip RN. Helicobacter pylori Infection-Challenges of Antimicrobial Chemotherapy and Emergence of Alternative Treatments. Trends in Helicobacter pylori Infection: IntechOpen; 2014.

24. Wanyama R, Obai G, Odongo P, Kagawa M, Baingana R. Effect of maternal Helicobacter Pylori infection on gestational weight gain in an urban community of Uganda. The Pan African medical journal. 2017;28.

25. Cardaropoli S, Rolfo A, Todros T. Helicobacter pylori and pregnancy-related disorders. World Journal of Gastroenterology: WJG. 2014;20(3):654.

26. Ugwuja El, Akubugwo El. Impact of Maternal Helicobacter pylori Infection on Trace Elements (Copper, Iron and Zinc) and Pregnancy Outcomes. Online Journal of Health and Allied Sciences. 2010;8(4).

27. Grooten IJ, Den Hollander WJ, Roseboom TJ, Kuipers EJ, Jaddoe VW, Gaillard R, et al. Helicobacter pylori infection: a predictor of vomiting severity in pregnancy and adverse birth outcome. American journal of obstetrics and gynecology. 2017;216(5):512. e1-. e9.

28. Nanbakhsh F, Mohaddesi H, Bahadory F, Amir Fakhrian J, Mazloomi P. Comparison of Helicobacter pylori infection between pregnant women with hyperemesis gravidarumand and controls. World Applied Sciences Journal. 2013;28(12):1918-22.

29. El-Garhy E, Wafa YA, Okasha A. Helicobacter Pylori Seropositivity in Hyperemesis Gravidarum During Pregnancy. The Egyptian Journal of Hospital Medicine. 2019;76(7):4616-21.

30. Xu M-Y, Cao B, Yuan B-S, Yin J, Liu L, Lu Q-B. Association of anaemia with Helicobacter pylori infection: a retrospective study. Scientific reports. 2017;7(1):13434. 
31. Awuku YA, Simpong DL, Alhassan IK, Tuoyire DA, Afaa T, Adu P. Prevalence of helicobacter pylori infection among children living in a rural setting in Sub-Saharan Africa. BMC public health. 2017;17(1):360.

32. Kalach N, Desrame J, Bonnet C, Commegeille P, Couturier D, Chaussade S, et al. Helicobacter pylori seroprevalence in asymptomatic pregnant women in France. Clin Diagn Lab Immunol. 2002;9(3):736-7.

33. Poveda GF, Carrillo KS, Monje ME, Cruz CA, Cancino AG. Helicobacter pylori infection and gastrointestinal symptoms on Chilean pregnant women. Revista da Associação Médica Brasileira. 2014;60(4):306-10.

34. Alvarado-Esquivel C. Seroepidemiology of Helicobacter pylori infection in pregnant women in rural Durango, Mexico. International journal of biomedical science: IJBS. 2013;9(4):224.

35. Cardaropoli S, Giuffrida D, Piazzese A, Todros T. Helicobacter pylori seropositivity and pregnancyrelated diseases: a prospective cohort study. Journal of reproductive immunology.2015;109:41-7.

36. Shabana AA, Sanad ZF, Alkelany OA, El Khouly NI, Hussain MM. Relationship between Helicobacter pylori infection and pre-eclampsia complicated by intrauterine growth restriction. Menoufia Medical Journal. 2016;29(3):705.

37. Elmahdy M, Sadek SS, Elmarsafawy A, Elkafash D, Elhenawy A. Incidence of helicobacter pylori infection in cases of hyperemesis gravidarum. Open J Obstet Gynecol. 2017;7(4):411.

38. Khalafulla $H$, Shahlol A, Nami A, editors. The prevalence of Helicobacter pylori Infection among pregnant women in south of Libya. HELICOBACTER; 2019: WILEY 111 RIVER ST, HOBOKEN 070305774, NJ USA.

39. Epstein A, Wing DA, Ouzounian JG, Miller DA, Lee RH. Helicobacter pylori and thrombocytopenia in the pregnant hispanic population. The Journal of Maternal-Fetal \& Neonatal Medicine. 2012;25(12):2588-90.

40. Abebaw W, Kibret M, Abera B. Prevalence and Risk Factors of H. pylorifrom Dyspeptic Patients in Northwest Ethiopia: A Hospital Based Cross-sectional Study. Asian Pacific Journal of Cancer Prevention. 2014;15(11):4459-63.

41. Abdella B, Ibrahim M, Tadesse I, Hassen K, Tesfa M. Association between Helicobacter pylori Infection and Occurrence of Anemia among Pregnant Women Attending Antenatal Care in Kulito Health Center, Halaba Zone, South Ethiopia, 2018. Anemia. 2020;2020.

42. Bekele A, Tilahun M, Mekuria A. Prevalence of anemia and Its associated factors among pregnant women attending antenatal care in health institutions of Arba Minch town, Gamo Gofa Zone, Ethiopia: A Cross-sectional study. Anemia. 2016;2016.

43. Mathewos B, Moges B, Dagnew M. Seroprevalence and trend of Helicobacter pylori infection in Gondar University Hospital among dyspeptic patients, Gondar, North West Ethiopia. BMC Research Notes. 2013;6(1):346.

44. ABBASALIZADEH S. The prevalence of helicobacter pylori infection among iranian pregnant womena meta-analysis study. 2016. 
45. Gasim GI, Elmugabil A, Hamdan HZ, Rayis DA, Adam I. O blood group as a risk factor for Helicobacter pylori IgG seropositivity among pregnant Sudanese women. Clinics and practice. 2017;7(3).

46. Parashi S, Bahasadri S, Alirezaiei M. Assessing the association between iron deficiency anemia and h. Pylori infection among pregnant women referring to a busy antenatal clinic in Tehran-Iran. Shiraz E-Medical Journal. 2013;14(3):153-61.

47. Ozaydin N, Turkyilmaz SA, Cali S. Prevalence and risk factors of helicobacter pylori in Turkey: a nationally-representative, cross-sectional, screening with the $13 \mathrm{C}$-Urea breath test. BMC Public Health. 2013;13(1):1215.

48. Lelissa D, Yilma M, Shewalem W, Abraha A, Worku M, Ambachew H, et al. Prevalence of anemia among women receiving antenatal care at Boditii Health Center, Southern Ethiopia. Age. 2015;15(19):25.

49. Azami M, Darvishi Z, Borji M, Sayehmiri K. Helicobacter pylori infection is associated with anemia in pregnant women-a meta-analysis study. Iran J Med Microbiol. 2016;10(1):1-7.

50. Kenea D, Negawo M, Lemessa F, Tejineh S. The magnitude and associated factors of Helicobacter pylori infection among adult dyspeptic patients attending Bokoji Hospital, Southeast Ethiopia. 2020.

\section{Tables}

Table-1: Sociodemographic characteristic of prevalence of helicobacter pylori infection 


\begin{tabular}{|c|c|c|c|}
\hline Variables & & Frequency $(n=290)$ & Percent (\%) \\
\hline \multirow[t]{6}{*}{ Age in years } & $<=19$ & 6 & 2.1 \\
\hline & $19-24$ & 74 & 25.5 \\
\hline & $25-29$ & 148 & 51.0 \\
\hline & $30-34$ & 43 & 14.8 \\
\hline & $35-39$ & 15 & 5.2 \\
\hline & $40+$ & 4 & 1.4 \\
\hline \multirow[t]{3}{*}{ Marital status } & Married & 268 & 92.4 \\
\hline & Single & 19 & 6.6 \\
\hline & Divorced & 3 & 1.0 \\
\hline \multirow[t]{4}{*}{ Educational status } & Unable to write and read & 16 & 5.5 \\
\hline & Able to write and read & 22 & 7.6 \\
\hline & Primary school & 132 & 45.5 \\
\hline & Secondary school and above & 120 & 41.4 \\
\hline \multirow[t]{5}{*}{ Occupation } & Farmer & 68 & 23.4 \\
\hline & Marchant & 32 & 11.0 \\
\hline & Governmental employee & 68 & 23.4 \\
\hline & Daily laborer & 18 & 6.2 \\
\hline & Housewife & 104 & 35.9 \\
\hline \multirow[t]{4}{*}{ Religion } & Orthodox Christian & 227 & 78.3 \\
\hline & Muslim & 32 & 11.0 \\
\hline & Catholic & 18 & 6.2 \\
\hline & Protestant & 13 & 4.5 \\
\hline \multirow[t]{3}{*}{ Family size } & $<=3$ & 192 & 66.2 \\
\hline & 4 & 48 & 16.6 \\
\hline & $>=5$ & 50 & 17.2 \\
\hline
\end{tabular}

Table 2: Bivariate and multivariate analysis for factors associated with Helicobacter pylori infection 


\begin{tabular}{|c|c|c|c|c|c|}
\hline \multirow[t]{2}{*}{ Variable } & & \multicolumn{2}{|c|}{$\begin{array}{l}\text { Helicobacter pylori } \\
\text { infection }\end{array}$} & \multirow[t]{2}{*}{$\begin{array}{l}\text { Crude } \\
\text { OR(95\% Cl) }\end{array}$} & \multirow[t]{2}{*}{$\begin{array}{l}\text { Adjusted } \\
\text { OR( }(95 \% \mathrm{Cl})\end{array}$} \\
\hline & & Yes (\%) & No (\%) & & \\
\hline \multirow[t]{2}{*}{ Residence } & Rural & $45(15.52 \%)$ & 193(66.55\%) & $\begin{array}{l}0.405(0.211 \\
0.777)^{\star \star}\end{array}$ & $0.415(0.120,1.437)$ \\
\hline & Urban & $19(6.55 \%)$ & $33(11.38 \%)$ & 1 & 1 \\
\hline \multirow[t]{4}{*}{ Gravidity } & I & 14)4.83\%) & $81(27.93 \%)$ & $\begin{array}{l}2.104(0.881 \\
5.026)^{\star}\end{array}$ & $\begin{array}{l}0.805(0.266 \\
2.438)\end{array}$ \\
\hline & II & $18(6.21 \%)$ & $78(26.9 \%)$ & $\begin{array}{l}1.576(0.683 \\
3.636)\end{array}$ & $\begin{array}{l}0.767(0.258 \\
2.281)\end{array}$ \\
\hline & III & $8(2.76 \%)$ & $46(15.9 \%)$ & $\begin{array}{l}2.091(0.769 \\
5.684)\end{array}$ & $\begin{array}{l}0.999(0.301 \\
3.311)\end{array}$ \\
\hline & IV or more & $12(4.13 \%)$ & $33(11.38 \%)$ & 1 & 1 \\
\hline \multirow{2}{*}{$\begin{array}{l}\text { Source of } \\
\text { drinking } \\
\text { water }\end{array}$} & Tap water & $14(4.83 \%)$ & $191(65.9 \%)$ & $\begin{array}{l}\text { 2.151(1.118, } \\
4.139)^{\star}\end{array}$ & $\begin{array}{l}0.902(0.324 \\
2.510)\end{array}$ \\
\hline & Well water & $18(6.21 \%)$ & $47(16.21 \%)$ & 1 & 1 \\
\hline \multirow{3}{*}{$\begin{array}{l}\text { Hand } \\
\text { washing } \\
\text { practice }\end{array}$} & Regularly & $19(6.55 \%)$ & $124(42.8 \%)$ & $\begin{array}{l}\text { 2.338(1.195, } \\
4.574)^{\star *}\end{array}$ & $\begin{array}{l}\text { 1.865(0.885, } \\
3.932)\end{array}$ \\
\hline & Sometimes & $9(3.10 \%)$ & $47(16.21 \%)$ & $\begin{array}{l}1.871(0.798 \\
4.386)\end{array}$ & $\begin{array}{l}3.090(1.144 \\
8.348)^{\star}\end{array}$ \\
\hline & $\begin{array}{l}\text { Immediately } \\
\text { after contact } \\
\text { with dirt }\end{array}$ & $24(8.28 \%)$ & $67(23.1 \%)$ & 1 & 1 \\
\hline \multirow{2}{*}{$\begin{array}{l}\text { Materials } \\
\text { used to wash } \\
\text { hands }\end{array}$} & $\begin{array}{l}\text { Water and } \\
\text { soap }\end{array}$ & $30(10.35 \%)$ & $81(27.93 \%)$ & $\begin{array}{l}0.378(0.205 \\
0.698) \star \star\end{array}$ & $\begin{array}{l}0.439(0.196 \\
0.983) \star\end{array}$ \\
\hline & Water only & $22(7.9 \%)$ & $157(54.14 \%)$ & 1 & 1 \\
\hline \multirow{2}{*}{$\begin{array}{l}\text { Feeding } \\
\text { unwashed } \\
\text { vegetables } \\
\text { and fruits }\end{array}$} & Yes & $21(7.24 \%)$ & $31(10.7 \%)$ & $\begin{array}{l}\text { 2.915(1.575, } \\
5.397)^{\star \star}\end{array}$ & $\begin{array}{l}2.279(1.031 \\
5.037) \star\end{array}$ \\
\hline & No & $158(54.5 \%)$ & $80(27.6 \%)$ & 1 & 1 \\
\hline \multirow[t]{2}{*}{$\begin{array}{l}\text { Feeding } \\
\text { spiced foods }\end{array}$} & Yes & $21(7.24 \%)$ & $145(50 \%)$ & $\begin{array}{l}\text { 2.302(1.248, } \\
4.245) \star *\end{array}$ & $\begin{array}{l}1.746(0.778 \\
3.916)\end{array}$ \\
\hline & No & $31(10.7 \%)$ & $93(32.1 \%)$ & 1 & 1 \\
\hline \multirow{2}{*}{$\begin{array}{l}\text { Availability of } \\
\text { latrine and its } \\
\text { usage habit }\end{array}$} & Yes & 35 & 17 & $\begin{array}{l}0.480(0.247 \\
0.933)^{*}\end{array}$ & $\begin{array}{l}\text { 1.118(0.400, } \\
3.124)\end{array}$ \\
\hline & No & 193 & 45 & 1 & 1 \\
\hline $\begin{array}{l}\text { Levels of } \\
\text { anemia }\end{array}$ & $7-9 \mathrm{~g} / \mathrm{dl}$ & $4(1.4 \%)$ & $19(6.55 \%)$ & $\begin{array}{l}0.867(0.272 \\
2.763)\end{array}$ & $\begin{array}{l}1.029(0.293 \\
3.613)\end{array}$ \\
\hline
\end{tabular}




\begin{tabular}{|c|c|c|c|c|}
\hline $9-11 \mathrm{~g} / \mathrm{dl}$ & $12(4.14 \%)$ & $65(22.41 \%)$ & $\begin{array}{l}0.988(0.467 \\
2.090)\end{array}$ & $\begin{array}{l}1.333(0.586 \\
3.032)\end{array}$ \\
\hline$>=12 \mathrm{~g} / \mathrm{dl}$ & $11(3.8 \%)$ & $17(5.9 \%)$ & $\begin{array}{l}0.282(0.118 \\
, 0.673) \star \star\end{array}$ & $\begin{array}{l}0.268(0.101,0 \\
.711)^{\star \star}\end{array}$ \\
\hline$<7 \mathrm{~g} / \mathrm{dl}$ & $25(8.62 \%)$ & $137(47.24 \%)$ & 1 & 1 \\
\hline
\end{tabular}

NB: ** is $P$-value $=<0.01, *$ is $P$ value $<0.05$

\section{Figures}

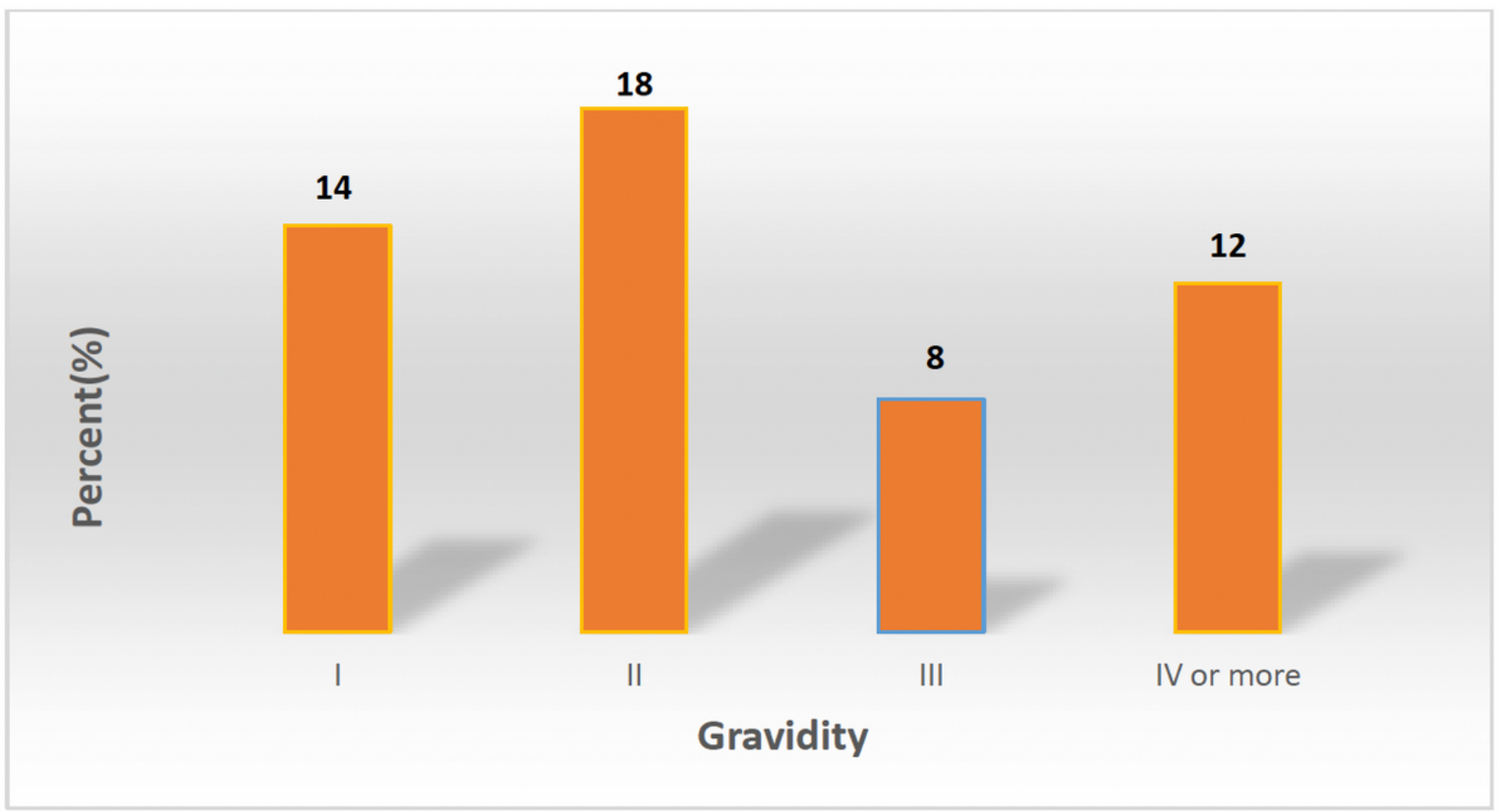

Figure 1

prevalence of Helicobacter Pylori infection among gravidity 


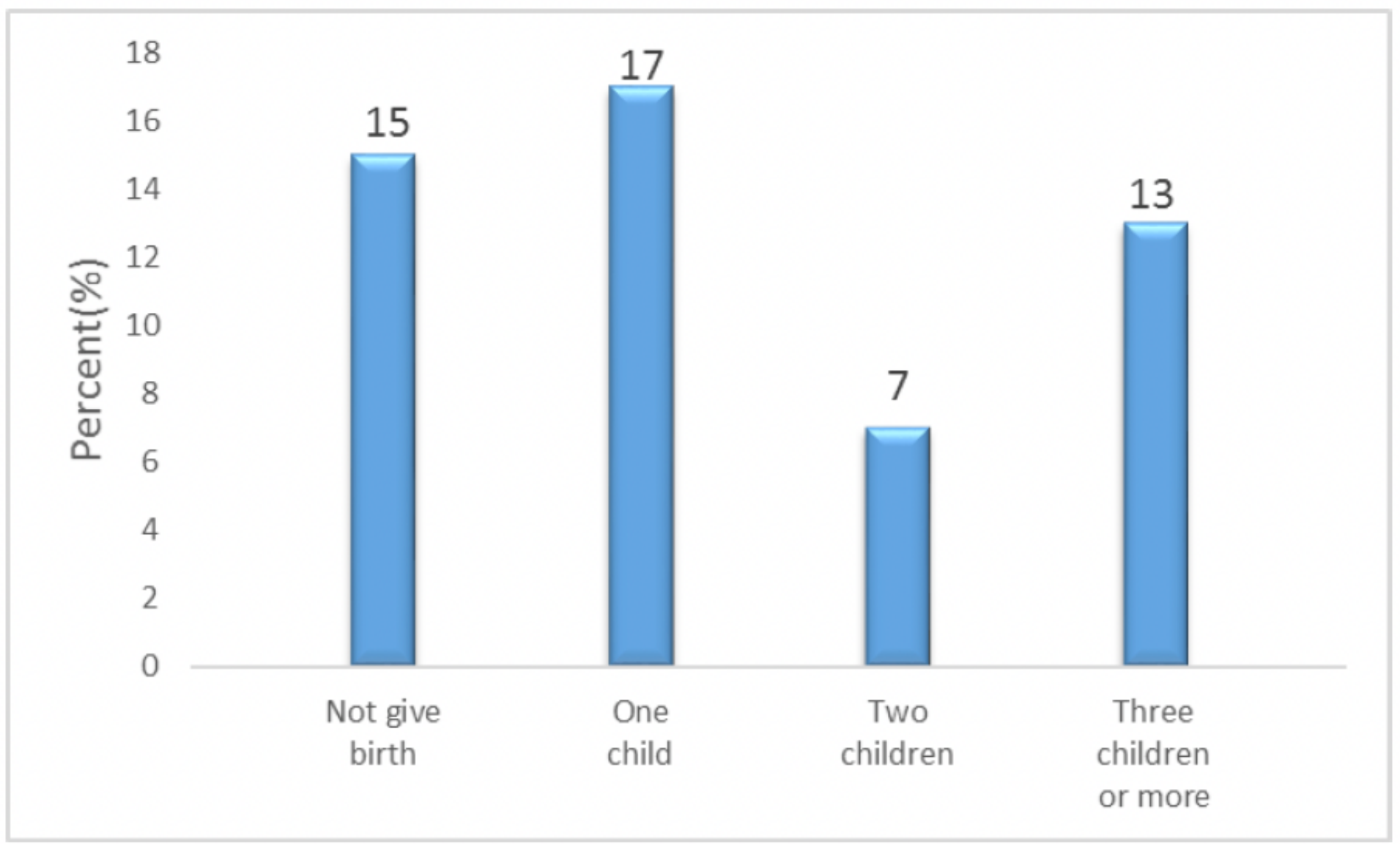

Figure 2

Prevalence of Helicobacter Pylori infection with parity. 